\title{
Interdiscurso, intertexto e práticas interpretativas: os processos de incorporação nas desnotícias
}

DOI: http://dx.doi.org/10.21165/el.v50i2.2994

\author{
Karina Rocha Campos ${ }^{1}$ \\ Jean Cristtus Portela²
}

\section{Resumo}

O presente artigo, parte da pesquisa realizada acerca do site Sensacionalista e do blog The Piauí Herald, tem como objetivo descrever o funcionamento da chamada prática desnoticiosa no que se refere aos processos de incorporação de tipo intertextual e interdiscursivo em suas composições. Partindo da clássica concepção de interdiscursividade e intertextualidade, pretende-se apresentar a noção de prática interpretativa inaugurada por Jacques Fontanille (2008), responsável por complexificar a questão ao alocar esses fenômenos em outro nível de pertinência. Além disso, procurase demonstrar, a partir de duas amostras de desnotícias, tais processos de incorporação em funcionamento, revelando as minúcias discursivas e destacando as especificidades de cada um dos veículos analisados.

Palavras-chave: desnotícias; interdiscurso; intertexto; práticas interpretativas; semiótica.

1 Universidade Estadual Paulista "Júlio de Mesquita Filho" (UNESP), Araraquara, São Paulo, Brasil; karina.campos@unesp.br; https://orcid.org/0000-0003-3132-2427

2 Universidade Estadual Paulista "Júlio de Mesquita Filho" (UNESP), Araraquara, São Paulo, Brasil; jean.portela@unesp.br; https://orcid.org/0000-0002-4070-1149 


\title{
Interdiscourse, intertext and interpretative practices: the processes of incorporation in satirical news
}

\begin{abstract}
The present article, part of the conducted research about the Sensacionalista website and The Piaui Herald blog, aims to describe the functioning and relevance of processes of intertextual and interdiscursive incorporation in the compositions of the so-called "satirical news". Starting from the classic concept of interdiscursivity and intertextuality, we intend to present the notion of interpretative practice inaugurated by Jacques Fontanille (2008), responsible for complexifying the issue by allocating this phenomenon in another level of pertinence. In addition, we seek to demonstrate, from two samples of satirical news, such processes of incorporation in operation, revealing the discursive details and highlighting the specificities of each of the vehicles analyzed.
\end{abstract}

Keywords: satirical news; interdiscourse; intertext; interpretative practices; semiotics.

\section{Introdução}

Nos últimos anos, os internautas brasileiros entraram em contato com uma nova prática discursiva que, impulsionada pelas redes sociais, alçou-se à popularidade: a prática desnoticiosa. Uma desnotícia caracteriza-se por ser um texto humorístico que reproduz as recorrências formais do gênero jornalístico a fim de parodiá-las, subvertendo o seu intuito noticioso original. No Brasil, considera-se que o gênero foi inaugurado a partir da criação do site Sensacionalista em 2009, coincidentemente o mesmo ano de criação do blog The Piaui Herald.

Ambos os veículos produzem textos que transitam entre a realidade do cotidiano e o absurdo das notícias inventadas, frequentemente confundindo internautas inadvertidos que julgam as desnotícias "reais". Acumulando mais de três milhões de curtidas no Facebook, o site Sensacionalista chegou a escrever desnotícias para alguns dos mais prestigiosos jornais e revistas do país, como a Veja ${ }^{3}$ e a Folha de S. Paulo ${ }^{4}$, o que prova a popularidade da prática desnoticiosa dentro e fora da internet. Já o blog The Piauí Herald é o braço humorístico da Revista Piauí, produzindo desnotícias com um humor aparentemente mais refinado, diferente daquele observado no site. Por isso, chamaram a atenção os mecanismos discursivos utilizados pelos enunciadores e os efeitos de sentido construídos desde a organização formal dos elementos presentes nas homepages até as minúcias argumentativas e modais existentes nos textos.

3 Disponível em: https://veja.abril.com.br/brasil/carta-ao-leitor-o-humor-do-Sensacionalistaagora-em-veja/. Acesso em: 3 set. 2019.

4 Disponível em: https://www1.folha.uol.com.br/colunas/Sensacionalista/2016/10/1826338-jantarde-temer-reune-por-engano-politicos-de-planilha-de-propinas.shtml. Acesso em: 3 set. 2019. 
No presente artigo, procura-se demonstrar como se dão os processos de incorporação de tipo interdiscursivo e intertextual nas composições desnoticiosas não apenas no nível dos textos-enunciados, mas também naquele dos objetos-suportes, posto que estes servem de superfície formal de inscrição dos textos e também fazem parte da produção de sentido. Partindo da concepção clássica de interdiscursividade e intertextualidade, procurar-se-á chegar às práticas interpretativas no modo como Jacques Fontanille (2008) as concebeu, a fim de apresentar a maneira que a disciplina semiótica encontrou de incorporar o lado de "fora" dos textos em suas análises.

Terminadas as discussões teóricas, será demonstrado a partir da análise das homepages dos veículos como a organização de elementos na superfície de inscrição formal a página web - é essencial ao sucesso da prática desnoticiosa como um todo. Será demonstrado também, agora no nível dos textos-enunciados e a partir de duas amostras de desnotícias, quais são as minúcias discursivas utilizadas pelos veículos, como se dão os processos de incorporação e quais são as principais especificidades de composição de cada um deles.

\section{Interdiscurso, intertexto e práticas interpretativas}

A noção de interdiscursividade sempre ocupou lugar cativo às teorias do discurso já que, para além de um simples processo de incorporação, é compreendida também enquanto aspecto inerente da linguagem. Relembrando Bakhtin (1993, p. 32 apud FIORIN, 2006, p. 167), não é possível ter a experiência do "dado puro" senão pela mediação da linguagem, isto é, pela "semiotização do mundo" (FIORIN, 2006, p. 167) pela qual ela é responsável.

Ao diferenciar interdiscursividade de intertextualidade, Fiorin parte de uma concepção de texto e de discurso que os encara do ponto de vista da estruturação linguística. Segundo o autor:

[...] o discurso é um todo organizado de sentido, delimitado por dois brancos, pertencente à ordem da imanência, ou seja, ao plano do conteúdo; é a atualização de virtualidades da língua e do universo do discurso. O texto também é um todo organizado de sentido, delimitado por dois brancos, mas é do domínio da manifestação, isto é, do plano da expressão; é a realização do discurso. (FIORIN, 2012, p. 154).

Essa concepção é parcialmente partilhada por autores como Jacques Fontanille (1999), que define o discurso enquanto o processo de significação, isto é, o ato e o produto de uma enunciação particular concretamente realizada. O texto, por sua vez, seria a organização de elementos concretos que permitem a expressão da significação desse discurso. Dessa forma, intertexto e interdiscurso não podem ser tomados enquanto sinônimos, mas sim como processos de incorporação que conjugam diferentes planos. 
Por definição, a interdiscursividade é um processo de incorporação que prevê a repetição de ideias, conhecida como citação, e a reutilização de temas e figuras enquanto horizontes de referência, a alusão. A intertextualidade, por sua vez, consiste num processo que faz entrecruzar materialidades já construídas, isto é, faz com que textos já conhecidos atravessem uns aos outros, modificando-os. A citação, um dos processos intertextuais, confirma ou altera o sentido de um texto que cita com as mesmas palavras; a alusão reproduz identicamente "construções sintáticas em que figuras são substituídas por outras" e a estilização consiste no processo de reprodução de um conjunto de procedimentos estilísticos de outrem (FIORIN, 1994). No entanto, os processos de alusão intertextual dependem do reconhecimento dos processos de incorporação interdiscursivos subjacentes, já que "o enunciado intertextual se refere diretamente à textualidade de um outro já dito, mas, além disso, se refere também ao discurso que esse último manifesta" (CAMPOS, 2019, p. 60 apud FIORIN, 1994, p. 35).

Sabe-se que a natureza parodística da prática desnoticiosa prevê o atravessamento de outros textos e discursos em seus enunciados por ser um tipo de discurso que, segundo Fávero (1994, p. 53), "engole e transforma o texto primitivo". No entanto, pode-se abordar essa necessidade de "atravessamento" a partir de outros pressupostos teóricos que os tradicionais citados acima.

Jacques Fontanille (2008), alicerçado nas bases epistemológicas que fundamentam a disciplina semiótica, foi responsável pela criação do chamado "percurso gerativo da expressão", um modelo teórico cujos níveis de pertinência traduzem as elaborações progressivas da experiência (SCHWARTZMANN, 2009), permitindo ao analista a abordagem tanto da dimensão material das semióticas-objeto, composta por signos, textos-enunciados e objetos-suportes, quanto da sua dimensão pragmático-cognitiva, que reúne as práticas e estratégias de composição. A regularidade desses processos culmina nas formas de vida, o nível mais complexo de pertinência semiótica que inaugura o caminho da disciplina em direção a uma tentativa de compreensão da cultura.

É no nível de pertinência das práticas, compreendido como o intermediário em que se observa a integração entre níveis inferiores e superiores com maior facilidade, que a prática interpretativa se encontra. Segundo Fontanille (2008), toda e qualquer prática, discursiva ou não, é organizada a partir de uma cena predicativa, isto é, um ato que compreende um operador, um objetivo e outras práticas com as quais ela interage. $O$ fazer persuasivo e o fazer interpretativo, de acordo com o autor (2008), incluem-se enquanto práticas por também serem dotados de uma estrutura sintagmática que assume forma de cena predicativa, articulando um ou mais processos e actantes.

O enunciador, cuja finalidade última ao produzir enunciados é obter a adesão de seu enunciatário, exerce o fazer persuasivo com vistas a fazê-lo crer; já o enunciatário, condicionado pelo fazer interpretativo, modaliza tais enunciados a partir dos planos 
de manifestação e imanência, isto é, decide pelo parecer e pelo ser daquilo que the é apresentado. Assim, no interior dos textos-enunciados, funda-se o chamado contrato fiduciário, o "pressuposto epistêmico básico de todo e qualquer ato enunciativo" (BALDAN, 1988, p. 49) e, ao nível da estrutura da enunciação, o contrato de veridicção, que se refere ao "dizer-verdadeiro" dos textos-enunciados em questão (GREIMAS; COURTÉS, 1979, p. 89).

Jacques Fontanille (2008), acerca dos fazeres persuasivo e interpretativo, afirma:

Consideradas como práticas, o fazer persuasivo e o fazer interpretativo não são mais atos simétricos, eles não se apoiam na mesma disposição fiduciária. O fazer persuasivo é um produtor de enunciados (ou qualquer outra forma semiótica) e crenças, destinados a desencadear outras práticas no enunciador, a começar pela prática interpretativa. [...] O fazer interpretativo também expressa crenças, só o faz no momento do trânsito que opera entre, por um lado, qualquer expressão semiótica, [...] e, por outro lado, outra produção semiótica, como o enunciado interpretativo. O enunciado interpretativo também pode integrar elementos do outro objeto semiótico, mas a principal relação não é a da integração, mas a da referência: o objeto semiótico a ser interpretado permanece sempre como horizonte referencial do ato interpretativo. Em suma, a "cena predicativa" da interpretação é, por natureza, mais complexa que a da persuasão, uma vez que estabelece uma relação entre dois objetos semióticos de natureza diferente, e que deve permanecer diferente, de modo que se pode falar de interpretação.

Assim, a prática interpretativa consiste, na verdade, numa tradução intersemiótica entre duas semióticas-objeto: aquela que funciona como horizonte referencial e aquela que é o objeto produzido pela prática em questão, ou seja, o enunciado interpretativo. De acordo com Fontanille (2008), a interpretação emerge do encontro entre enunciado interpretativo e o chamado horizonte referencial.

As instâncias da cena interpretativa são três actanciais e uma predicativa (FONTANILLE, 2008): o ato interpretativo, que consiste na prática de interpretação, o actante interpretante, o enunciado interpretativo e o que Fontanille chama de "outra cena", o horizonte referencial supracitado. A designação dada pelo autor - "outra cena" - causa estranhamento, mas se mostra válida para a análise, posto que se refere à cena a qual o enunciado faz referência. A fim de esquematizar todas essas relações, Fontanille organiza um modelo triádico das instâncias da cena interpretativa, reproduzido integralmente abaixo: 
Figura 1. Modelo triádico das instâncias da cena interpretativa

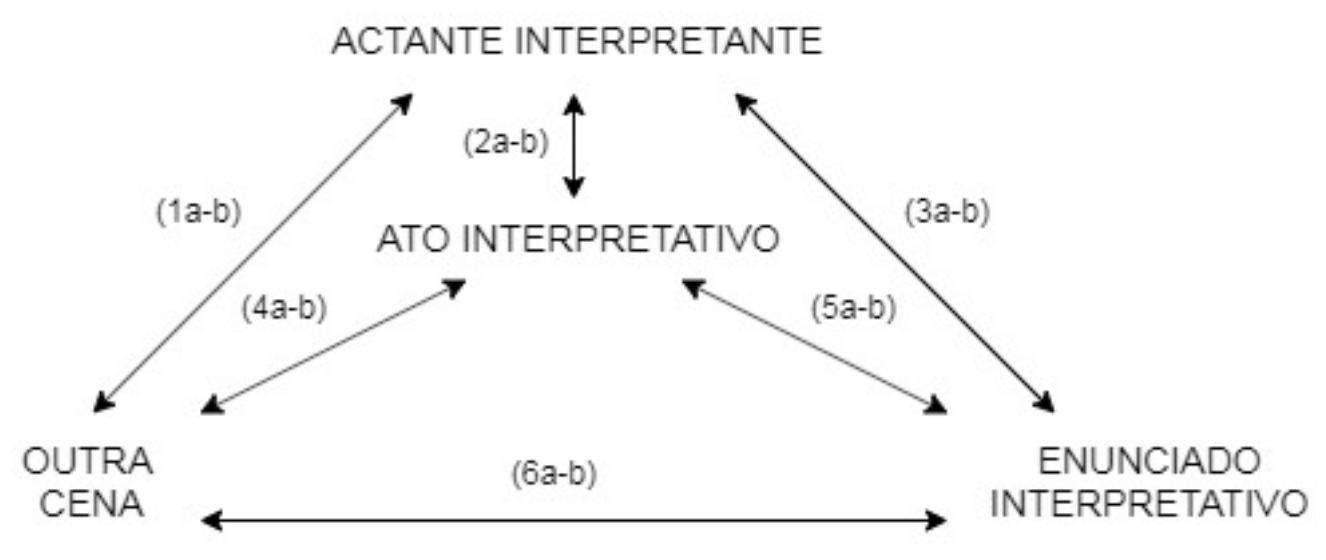

Fonte: Fontanille 2008, p. 97 (tradução nossa)

Como se vê, as relações interdiscursivas e intertextuais, em Fontanille, são complexificadas a partir da instauração de instâncias actanciais e predicativas que levam os processos de incorporação a outro nível de pertinência. 0 eixo $6 a$ e $6 b$ demonstra que a reconstrução das "outras cenas", isto é, dos horizontes referenciais, é uma operação obrigatória à interpretação dos "enunciados interpretativos"; nas desnotícias, essa operação é a grande responsável pelo desencadeamento do humor.

A abordagem fontanilliana da prática de interpretação analisa a competência exigida do enunciatário por parte do enunciador. No caso da prática desnoticiosa, é a capacidade de reconstrução das cenas interpretativas que leva o enunciatário a compreender integralmente os textos humorísticos; caso não seja dotado dos saberes referentes ao horizonte referencial que serve de base à construção do texto desnoticioso, este se resumirá apenas a um enunciado sem sentido, confuso, duvidoso e improvável. 0 horizonte referencial em si também é dotado de cenas predicativas e interpretativas, sendo passível de interpretações extras a fim de reconstruir completamente o sentido do enunciado interpretativo original.

De acordo com Campos (2019), o gênero jornalístico comum não exige a realização dessa reconstrução de outras cenas, já que, frequentemente, a própria reportagem traz a "outra cena" no corpo de seu texto. No gênero desnoticioso, ao contrário, "refrescar" a memória do enunciatário prejudica o potencial humorístico do texto, pois, como afirma Beth Brait (2008), é na tensão entre o dito e o não-dito que se flagra um enunciado irônico ou humorístico. O efeito de humor surge justamente na escolha que o enunciatário faz por um dos sentidos veiculados pelos enunciadores, o virtualizado ou aquele que está em presença no enunciado. 
Nas seções a seguir, observaremos como os enunciadores desnoticiosos selecionam e organizam os horizontes referenciais em dois momentos: 1. ao construir as homepages de seus sites e 2. ao compor os textos desnoticiosos. No primeiro momento, permaneceremos no nível dos objetos-suportes, analisando os elementos formais dispostos na página web, o suporte formal dos veículos em questão; no segundo, debruçar-nos-emos no nível dos textos-enunciados, analisando os textos integrais de duas desnotícias, uma pertencente ao site Sensacionalista e outra ao blog The Piauí Herald. Assim, será possível delinear as principais semelhanças e divergências de composição de cada um dos veículos em questão.

\section{O site Sensacionalista e o blog The Piauí Herald}

A prática desnoticiosa é composta de diversos aspectos que garantem sua eficácia. Para além das subversões enunciativas e sutilezas de sentido encontradas no nível dos textosenunciados, a organização formal da página web em que esses textos circulam oferece pistas de como essa prática se organiza e com quais outras práticas ela interage. Por isso, a análise minuciosa dos componentes faz-se importante na medida em que revela como o sentido é construído a partir dessa organização em nível formal.

Como se viu, ambos, site e blog, foram inaugurados em 2009 e, desde então, são acessados pelos internautas a partir dos endereços URL "sensacionalista.com.br" e "piaui.folha.uol. com.br/herald/"5, respectivamente. Como afirma Campos (2019), esse primeiro dado acerca dos veículos é importante porque é parte do modo de circulação dos textos pela internet, configurando um elemento essencial a um gênero que se constrói em ambiente virtual. Por se tratar de um elemento enunciativo que se encontra fora da propriedade textual em si, os endereços revelam logo de início uma discrepância entre os veículos que, com o aprofundamento das análises, intensifica-se.

No caso do site Sensacionalista, o domínio próprio "sensacionalista.com.br" aponta para uma coincidência entre a designação e o produto, pois encontra-se no endereço virtual o mesmo nome dado ao site. Além disso, a instância enunciante também é a mesma, o que nos possibilita afırmar que se estabelece uma relação de debreagem enunciativa entre todos esses elementos. Observa-se, portanto, que o site se apresenta como uma entidade independente, posto que se autodenomina inclusive nos domínios extratextuais (CAMPOS, 2019).

Já o blog The Piauí Herald conta a forte presença de sua matriz, a Revista Piauí, desde seu endereço URL; em "piaui.folha.uol.com.br/herald/", percebe-se que, primeiramente, se vê

5 Uniform Resource Locator, um "formato de designação universal para designar um recurso na internet". É composto de um protocolo, o nome do servidor e o caminho onde se encontra tal recurso. http://br.ccm.net/contents/288-url. Acesso em: 19 set. 2018. 
o domínio referente à Revista, depois à Folha de S. Paulo, depois à UOL e só então se lê "herald", entre duas barras diagonais. Aqui, o blog encontra-se descolado em termos de autonomia do objeto que permite sua circulação, configurando uma debreagem enunciva e sugerindo a existência de uma relação de subordinação entre o blog desnoticioso e a Revista (CAMPOS, 2019).

A organização formal dos elementos nas homepages de cada um dos veículos é o que eles mais têm em comum, posto que ambos procuram lançar mão de configurações cujos efeitos de sentido passem a sensação de verdade a seus enunciatários. Para isto, buscam no já estabilizado gênero jornalístico as mesmas estratégias de composição de jornais prestigiosos, bem como elegem enquanto horizontes referenciais elementos visuais que provoquem familiaridade. Assim, incorporando às suas homepages elementos pertencentes ao "discurso de outrem, isto é, do estilo de outrem" (FIORIN, 1994, p. 31), os veículos desnoticiosos lançam mão do processo de incorporação intertextual da estilização para construir sua dimensão formal.

Um bom primeiro exemplo do empréstimo de elementos do discurso de outrem é a fonte que grafa o título do jornal The New York Times, "Old English". Quando a página inicial de ambos os veículos desnoticiosos é carregada, observa-se que os enunciadores fizeram a escolha pela mesma fonte para estampar o topo da página, procurando utilizá-la como efeito de sentido de verdade aos enunciatários que recuperam o prestigioso jornal americano enquanto horizonte de referência para a interpretação do enunciado.

Ainda na porção superior da página em que os veículos se inscrevem, observa-se a presença de um slogan logo abaixo do título "Sensacionalista". Segundo Nilton Hernandes (2006, p. 40), os slogans têm papel importante nos jornais porque "ilustram bem as cláusulas desse contrato fiduciário que se funda na criação de desejos, ou obrigações, ou ainda em ambas as estratégias". No caso do site, o slogan instaura ambiguidade ao afirmar ser "isento de verdade"; aqui, "de verdade" pode funcionar ou como um complemento nominal, que aponta para a "isenção" e sugere que o site não veicula verdade alguma, ou como um advérbio, indicando que o site é "realmente isento" de qualquer tipo de enviesamento. Os enunciadores do Sensacionalista inserem, assim, um protocolo de abertura capaz de reconfigurar o contrato fiduciário, já que sugere que os discursos a serem proferidos ali podem estar, ou não, ao modo do não-ser e do não-crer-ser verdadeiros (CAMPOS, 2019).

Além do slogan, o site Sensacionalista utiliza também seções para organizar seu conteúdo. Como se observa logo abaixo do título, vê-se várias palavras em negrito dispostas uma ao lado da outra funcionando como hiperlink: "Home", "Vídeos", "País", "Esporte", "Entretenimento", "Mundo", etc. Ao clicar em uma delas, o internauta é redirecionado a outra página que reúne todas as desnotícias que tratam de assuntos relacionados. Tal ferramenta inexiste no blog The Piauí Herald que, apesar de "etiquetar" cada um de seus textos com o assunto a que eles se referem, não disponibiliza hiperlinks que permitam fácil acesso a um conjunto de textos. 
Na porção intermediária da página, onde as desnotícias de fato são apresentadas, observa-se que ambos os veículos obedecem a preceitos da enunciação jornalística ao alocar as três desnotícias mais recentes no topo da página, acompanhadas de fotos e manchetes em letras maiores. De acordo com Hernandes (2006), a estratégia tem como objetivo produzir o efeito de atualidade, isto é, destacar unidades desnoticiosas que pareçam presentificadas e vibrantes a partir da instauração de um presente "elástico", pois, ainda segundo o autor: "O poder de mobilização afetiva das unidades noticiosas se vincula fortemente ao período da edição na qual estão inseridas, ao sentido de atualidade. Noticiário antigo não emociona. Ou, pelo menos, tem o impacto afetivo bastante alterado." (HERNANDES, 2006, p. 54).

Quanto às desnotícias mais antigas, site e blog as organizam de modo diferente. O site Sensacionalista adota um layout diverso, por vezes dividindo as desnotícias em duas ou três colunas, com manchetes acompanhadas ou não de imagem ilustrativa. Como se espera, a disposição obedece a preceitos da hipertextualidade, que transforma cada uma das manchetes e reportagens num centro de leitura e possibilita inúmeros caminhos de leitura ao internauta (CAMPOS, 2019). O blog, por sua vez, também preserva as características hipertextuais próprias do ambiente virtual, mas é mais econômico, pois disponibiliza textos mais antigos a partir de uma única coluna vertical denominada "últimas"; quase ao pé da página, quando as manchetes da coluna chegam ao final, o internauta se depara com o botão "Mais textos", encarregado de mostrar desnotícias ainda mais antigas. Assim, o blog gera um tipo de infinite scrolling ${ }^{6}$ a seu leitor, permitindo que ele navegue por todo o conteúdo sem sair da página inicial.

Diferentemente do site Sensacionalista, o blog coloca data e hora em cada um dos seus textos, disponibilizando assim um "Arquivo" que permite que o internauta navegue por desnotícias de meses e anos atrás. No site há uma ausência completa de registros temporais nas desnotícias, o que faz parte da estratégia de circulação de seus textos. Assim, aqueles mais genéricos, que não contam com acontecimentos pontuais, ancorados por antropônimos específicos e topônimos, podem se ajustar a qualquer momento em que são lidos, aumentando seu potencial de circulação e impacto (CAMPOS, 2019).

Elementos como a fonte utilizada pelos veículos e o plano de fundo de cada um deles também revelam os valores que ambos procuram mobilizar e os sentidos que procuram construir. No site Sensacionalista, vê-se que os textos e as manchetes são escritos em fonte não serifada, procurando transmitir a sensação de modernidade em sua homepage uma vez que as fontes simples, geométricas e sem serifas estão associadas ao advento da sociedade industrial, que busca produzir variedades tipográficas que se adaptem aos textos informativos, impessoais e objetivos (CARVALHO, 2013). Além disso, as fontes

6 "Scroll Infinito é um plugin de JavaScript que automaticamente adiciona a página seguinte na atual, poupando os usuários da necessidade de carregar manualmente uma nova página. É provável que você já tenha visto esse plugin em uso por toda a Internet". https://infinite-scroll.com. Acesso em: 19 ago. 2018. 
sem serifas são ideais para textos concebidos para a internet, o que vai ao encontro do fato de que estas são amplamente utilizadas por portais virtuais de notícia, como o G1 e o R7. Já o blog faz a escolha por fontes serifadas não apenas para o seu título, mas para as manchetes e reportagens como um todo, lançando mão de elementos visuais que o atrelam a valores mais tradicionais, já que fontes caracterizadas pelas serifas baseiam-se em modelos de escrita manual, trazendo à tona valores associados à cultura e à história (CARVALHO, 2013). Como exemplo, tem-se jornais mais tradicionais, como a Folha de S. Paulo, que mesmo em sua versão virtual preza pelo uso de fontes serifadas para seus textos.

O plano de fundo utilizado por cada um dos veículos vai ao encontro dessas hipóteses, pois o blog procura emular não só a cor acinzentada do tradicional papel de jornal como também as características das manchas típicas do processo químico pelo qual ele passa para ser produzido. Em oposição a isso, tem-se o fundo brando simples do site Sensacionalista, próprio de um portal virtual comum (CAMPOS, 2019).

Por fim, os espaços em branco na homepage do site Sensacionalista são preenchidos por propagandas alimentadas pelo histórico de busca do internauta, o que acaba funcionando também como um efeito de sentido de realidade já que esse tipo de anúncio se faz presente em páginas de jornais tradicionais e portais de notícia. Já no blog, toda a publicidade e os espaços em branco são voltados à divulgação da Revista Piauí, seja por meio de anúncios, hiperlinks e imagens, reforçando ainda mais a hipótese de subordinação do blog à sua matriz.

Percebe-se, portanto, que o processo de incorporação intertextual da estilização é o que fundamenta a organização de elementos formais das homepages dos veículos analisados. A reprodução do estilo de jornais tradicionais, aqui compreendido enquanto "o conjunto das recorrências formais tanto no plano da expressão quanto no plano do conteúdo (manifestado, é claro) que produzem um efeito de sentido de individualização" (BERTRAND, 1985 apud FIORIN, 1994), se dá a partir de diversos componentes, sendo essencial à sátira pretendida pelo site e blog.

\section{As composições desnoticiosas: duas amostras}

A produção desnoticiosa de ambos os veículos analisados difere-se para além das minúcias enunciativas que serão reveladas na presente seção. Como apontou Campos (2019), site e blog produzem textos em ritmo, quantidade e temática diferentes, o que obrigou o refinamento do critério de seleção do córpus para análise?

7 Os pormenores acerca do critério de seleção do córpus podem ser consultados na dissertação de mestrado da autora que originou o presente trabalho. Disponível em: https://repositorio.unesp. br/handle/11449/180996. Acesso em: 18 set. 2019. 
Para o presente trabalho, foram escolhidas duas desnotícias de cunho sociopolítico em que as principais características de cada um dos veículos se destacam, sendo possível observar quais semelhanças os aproximam e quais divergências os distanciam. Ambas foram coletadas nos meses de março e abril do ano de 2018. Assim, serão observados os horizontes referenciais evocados pelo site e blog, os processos de incorporação interdiscursivos e intertextuais necessários à correta interpretação dos textos humorísticos, bem como outras minúcias enunciativas detectadas.

A primeira desnotícia a ser analisada ${ }^{8}$, pertencente ao site Sensacionalista, fora encomendada para a Revista Veja. Na manchete, lê-se: "PF tem mandado com lacuna para próximo candidato do $\mathrm{PT}^{\prime \prime}$. Em seguida, no corpo do texto, lê-se:

Após revistar a casa de Jaques Wagner e levar papéis e computadores, a PF conseguiu na Justiça um mandado de busca com o espaço para o nome do próximo plano B do PT em branco. "Não queremos que achem que é perseguição", disse um delegado da PF. "Por isso, quando um novo candidato surgir, mostramos que o mandado para entrar em sua casa foi lavrado muito antes. Só o nome que é colocado no dia."

A direção do PT diz que planeja circular o nome de Aécio Neves como novo plano B de Lula só pelo prazer de vê-lo ser investigado. Na casa de Wagner, a PF encontrou relógios de luxo e suspeita que sejam presentes de empreiteiras. Por coincidência, todos os relógios estavam sincronizados e apontavam a mesma hora: hora de o PT tomar vergonha na cara.

Logo de início, emerge, isto é, vai da virtualização à atualização, a grandeza discursiva da hipótese de "perseguição" contra o Partido dos Trabalhadores, a partir de "mandado", "lacuna" e "candidato do PT" presentes na manchete. No texto, temos a confirmação de que se trata de uma trama para inviabilizar a candidatura de qualquer representante do PT nas eleições presidenciais, especialmente no trecho: "A direção do partido diz que planeja circular o nome de Aécio Neves como plano B de Lula só pelo prazer de vê-lo ser investigado". Aqui, fica clara que tal hipótese, na verdade, se trata de ponto pacífico, pois tanto os actantes coletivos "direção do partido" e "PF" partilham da mesma configuração para pensar suas estratégias de ação.

8 A presente análise foi retirada integralmente, porém com ajustes, da dissertação de mestrado da autora que originou o presente trabalho. Disponível em: https://repositorio.unesp.br/ handle/11449/180996. Acesso em: 18 set. 2019.

9 Disponível em: https://veja.abril.com.br/blog/sensacionalista/pf-tem-mandado-com-lacunapara-proximo-candidato-do-pt/. Acesso em: 18 set. 2019. 
Ademais, na mesma passagem o enunciador escolhe a figura de Aécio Neves para realizar a grandeza discursiva da "impunidade". Aqui, ao colocá-lo como opção para o "plano B de Lula só pelo prazer de vê-lo ser investigado", o enunciador assere a primeira evidência apontada, de que existe perseguição contra o Partido dos Trabalhadores, e deixa implícito que Aécio Neves é um político frequentemente poupado por investigações policiais.

No primeiro parágrafo da desnotícia, a trama é detalhada a partir da figura do ator Jaques Wagner: "Após revistar a casa de Jaques Wagner e levar papéis e computadores, a PF conseguiu na Justiça um mandado de busca com o espaço para o nome do próximo plano B do PT em branco". Os motivos pelos quais "Jacques Wagner" teve documentos apreendidos não é citado, porém deve ser recuperado pelo enunciatário a partir do reconhecimento do horizonte referencial lançado mão pelo enunciador, que diz respeito às investigações por suspeitas de superfaturamento de obras públicas ${ }^{10}$, o que deve atualizar a grandeza discursiva da "corrupção".

Além disso, observa-se que o "mandado de busca com o espaço [...] em branco" se apresenta como um objeto modal com o qual o actante coletivo PF está em conjunção para desempenhar sua performance principal, que é "buscar" (inviabilizar) o próximo plano B do PT. Nesse momento, outro horizonte referencial relativo ainda ao ator "Jacques Wagner" é explorado pelo enunciador: no começo do ano, o político foi cotado como preferido por lideranças mais tradicionais do PT para figurar como plano B caso a candidatura de Lula fosse impugnada, o que justifica o enunciador desnoticioso utilizá-lo como figura para tratar do tema "perseguição" já atualizado. Wagner, porém, refutou a possibilidade de concorrer à presidência ${ }^{11}$.

Em seguida, a estratégia da PF é esmiuçada a partir de uma debreagem interna de segundo grau, a fala do "delegado da PF", para conferir veracidade à manchete: "Não queremos que achem que é perseguição. [...] Por isso, quando um novo candidato surgir, mostramos que o mandado para entrar em sua casa foi lavrado muito antes. Só o nome é colocado no dia". Assim, o conluio anteriormente atualizado agora se realiza a partir da fala do ator que, apesar de negar que se trata de "perseguição", descreve com exatidão uma maneira de perseguir grupos políticos. Isso se realiza a partir de "mandado [...] lavrado muito antes" e "Só o nome é colocado no dia". O objeto de valor do actante coletivo "PF", portanto, é a inviabilização da candidatura do PT às eleições presidenciais, e com os mandados em branco eles adquirem o poder-fazer necessário para dar cabo de sua performance principal que, na presente desnotícia, é sancionada positivamente.

10 Disponível em: https://glo.bo/3wmUbzL. Acesso em: 18 set. 2019.

11 Disponível em: https://epoca.globo.com/jaques-wagner-diz-haddad-que-articula-para-ser-vicede-ciro-caso-candidatura-de-lula-seja-impedida-22942988. Acesso em: 18 set. 2019. 
No segundo e último parágrafo, o texto abaixo da manchete é repetido e, em seguida, ocorre uma clara manifestação do enunciador: "Na casa de Wagner, a PF encontrou relógios de luxo e suspeita que sejam presentes de empreiteiras. Por coincidência, todos os relógios estavam sincronizados e apontavam a mesma hora: hora de o PT tomar vergonha na cara".

Até esse momento, a desnotícia fora composta tal qual uma unidade noticiosa comum, já que se observa a ampla utilização da debreagem actorial, espacial e temporal de natureza enunciva tanto na manchete quanto no corpo do texto. No entanto, nessa última passagem os enunciadores lançam mão do episódio em que relógios de luxo são apreendidos na residência do ex-governador da Bahia ${ }^{12}$ e utilizam o mesmo campo semântico para "desabafar" sobre o Partido dos Trabalhadores: "[é] hora de o PT tomar vergonha na cara". Esse trecho se destaca por se caracterizar pelo explícito julgamento de quem concebeu a desnotícia, destoando assim do resto do texto e reforçando seu caráter inverossímil. Assim, o momento de desabafo dos enunciadores é importante na medida em que serve de elemento de análise e aproximação do sujeito da enunciação, que se deixa finalmente vislumbrar.

Observa-se que a tomada de posição dos sujeitos da enunciação revela um apoio crítico ao partido, pois ao mesmo tempo que denunciam um conluio contra ele, atualizando e realizando formas discursivas que apontam para uma perseguição ao PT por parte das autoridades, denunciam também a má conduta de alguns de seus membros, pois "perdem a paciência" nas últimas linhas da desnotícia ao citarem o episódio de apreensão dos relógios de luxo na residência de Jaques Wagner e concluem que o partido precisa dar um basta nas atividades ilegais que perpetuam. No trecho, o tema da "corrupção" é figurativizado pelos "relógios de luxo". Revela-se, então, um fragmento advindo do ethos das inteligências enunciativas por detrás das composições do site Sensacionalista.

Assim, os atores da desnotícia, o "delegado da PF", "Aécio Neves" e "Jaques Wagner", determinados como "ele" pela sintaxe discursiva, têm seus percursos narrativos revestidos pelas temáticas da "perseguição", do "conluio", da "impunidade" e da "corrupção", a partir de investimentos figurativos como "mandado", "plano B de Lula" e "relógios de luxo". Os enunciadores não têm o objetivo de informar o enunciatário sobre a investigação de Wagner ou sobre a atuação da Polícia Federal, mas sim de criticar as ações da instituição a partir da sátira desses episódios, buscando a adesão e assunção do enunciatário a partir da utilização das imagens citadas.

Tais elementos, quando somados à atuação da sintaxe discursiva responsável por conferir os efeitos de sentido de objetividade, atualidade e distanciamento, configuram o fazer-

12 Disponível em: https://politica.estadao.com.br/blogs/fausto-macedo/pf-apreende-15-relogiosde-luxo-com-jaques-wagner/. Acesso em: 18 set. 2019. 
crer desnoticioso dos enunciadores, que, nessa desnotícia, possui um tom denunciatório bastante marcado, além de uma clara manifestação pessoal.

A segunda desnotícia analisada ${ }^{13}$, pertencente ao blog The Piauí Herald, é também de temática sociopolítica; elege como assunto o julgamento do ex-presidente Lula e explora um campo semântico bastante específico para fazê-lo, como se vê logo a partir da manchete: "Merval Pereira vai fechar o Maracanã no julgamento de Lula"14. Reproduzimos o texto integral da desnotícia abaixo:

LULLAPALOOZA - Freddie Mercuryval Pereira, o líder da banda Queen, confirmou que vai fechar mesmo o estádio do Maracanã, na tarde desta quarta-feira, para transmitir ao vivo o julgamento do ex-presidente Lula no STF. "É o maior festival de heavy metal jurídico já organizado nesse país", celebrou o mercurial Mercuryval, que promete tocar os grandes sucessos que o consagraram, como "Lula of My Life" e "Radio Lu La". "E vai ter também aquele single da conversa entre o Lula e a Dilma lançado pelo AxI Moro!"

Mercuryval contou que o show deve começar pontualmente às duas da tarde, com a abertura dos New Kims on the Block, a boy band estriônica do MBL. Logo depois ele sobe ao palco para fazer um dueto com o rockstar anglo-curitibano Deltan John. Em seguida, Mercuryval cede os vocais para a transmissão, ao vivo, do voto da ministra Rosa Weber, a Rita Lee do Supremo.

Os ingressos para o festival estão à venda em todos os grupos de família do WhatsApp. Ainda há lugares disponíveis no Camaroti, o camarote do Camarotti.

O que chama atenção logo de início é o topônimo que os enunciadores atribuem, "Maracanã", ao acontecimento de um evento jurídico, o "julgamento de Lula". Tratando-se de um estádio de futebol, o que se atualiza aos enunciatários é a hipótese de que tal evento consista numa "cerimônia" ou num "espetáculo" de grande porte, posto que o Maracanã é o maior estádio de futebol do país com capacidade para acomodar mais de setenta mil pessoas $^{15}$. $O$ actante que faz o anúncio, Merval Pereira, também chama atenção, pois se trata de um jornalista, escritor, comentarista político e membro da Academia Brasileira de

13 A segunda análise, assim como a primeira, também foi retirada integralmente da dissertação de mestrado da autora que originou o presente trabalho. Disponível em: https://repositorio.unesp. br/handle/11449/180996.

14 Disponível em: https://piaui.folha.uol.com.br/herald/2018/04/03/merval-pereira-vai-fechar-omaracana-durante-o-julgamento-de-lula/. Acesso em: 18 set. 2019.

15 Disponível em: https://super.abril.com.br/mundo-estranho/o-maracana-ainda-e-o-maiorestadio-do-mundo/. Acesso em: 18 set. 2019. 
Letras, autor de vários livros, como O lulismo no poder (2010) e Mensalão: o dia a dia do mais importante julgamento da história política do Brasil (2013). Os enunciadores elegem como actante, portanto, uma figura pertencente a um grupo específico que, caso o enunciatário não esteja familiarizado, não se dará conta de quem se trata.

No primeiro parágrafo da desnotícia, os enunciadores lançam mão de outro topônimo em letras maiúsculas para ancorar a unidade desnoticiosa num determinado local, assim como fazem unidades noticiosas comuns. Observa-se que essa estratégia é normalmente utilizada em composições do blog, o que indica que é uma prática comum que procura emular o máximo possível de elementos emprestados do gênero jornalístico. O topônimo em questão explora a aliteração existente em "Lula" e "Lollapalooza", um famoso festival de música ${ }^{16}$, para criar o "Lullapalooza". Assim, os enunciadores inauguram o campo semântico escolhido para compor a desnotícia, o da música, logo na primeira palavra que se lê no corpo da desnotícia.

Em seguida, dá-se o início da desnotícia: "LULLAPALOOZA - Freddie Mercuryval Pereira, o líder da banda Queen, confirmou que vai fechar mesmo o estádio do Maracanã, na tarde desta quarta-feira, para transmitir ao vivo o julgamento do ex-presidente Lula no STF". Observa-se a criação de novos nomes a partir de semelhanças fonéticas não se restringe ao topônimo utilizado, mas estende-se também ao nome do actante "Merval Pereira" que vira "Freddie Mercuryval Pereira", em referência a Freddie Mercury, líder da banda inglesa de rock Queen, como o próprio trecho afirma. No restante do trecho, impera a utilização da terceira pessoa e do tempo do "então" para relatar o anúncio do fechamento do Maracanã para a transmissão ao vivo do julgamento do ex-presidente Lula, exatamente como uma unidade noticiosa comum noticiaria. Até o momento, o percurso narrativo que o texto explora é o da busca por entretenimento, e o realiza a partir de revestimentos figurativos que evocam no enunciatário o sentido de irrealidade, pois, reconhece que determinados antropônimos foram utilizados para especializar o actante apresentado até agora a fim de criar uma ilusão referencial absurda: uma mistura entre um vocalista de uma banda de rock e um jornalista.

A forma discursiva do "espetáculo" continua a ser atualizada no trecho, passando à realização na fala de "Mercuryval":

"É o maior festival de heavy metal jurídico já organizado nesse país", celebrou o mercurial Mercuryval, que promete tocar os grandes sucessos que o consagraram, como "Lula of My Life" e "Radio Lu La". "E vai ter também aquele single da conversa entre o Lula e a Dilma lançado pelo Axl Moro!"

16 Disponível em: https://www.lollapalooza.com/. Acesso em: 18 set. 2019. 
A partir da primeira fala de "Mercuryval", percebe-se que, de fato, o julgamento do expresidente Lula é descrito como um "festival de heavy metal jurídico" para demonstrar que se trata de um momento de entusiasmo, agitação e animação. Assim, justifica-se a realização do evento num estádio de grande porte como o "Maracanã", realizando a forma discursiva do "espetáculo" e da "euforia". Pode-se observar que a realização dessa grandeza está em constante aparecimento, posto que o tratamento dado ao tópico em outras desnotícias do blog também é de um grande "evento", evidenciando como as inteligências enunciativas por trás da composição do blog mantém um forte elo com essa forma discursiva, bem como a veiculam em um grande número de ocorrências. Assim, sua forte assunção e seu extenso reconhecimento a amplificam, integrando-a ao rol de usos correntes do blog no momento de satirizar esse episódio.

Os enunciadores utilizam o adjetivo "mercurial" para descrever o actante "Mercuryval" e instalam uma evidente ambiguidade: esse adjetivo advém de "mercúrio" e o registro de seu uso coloquial tem o significado de "censura severa"17. A imprensa brasileira chegou a utilizar o adjetivo para qualificação de determinado indivíduo como "temperamental" ou "volátil", sentido provavelmente emprestado do significado da palavra em inglês ${ }^{18^{-19}}$. Assim, aliando o nome artístico escolhido para "Merval Pereira", os enunciadores revelam uma escolha lexical distinta e enriquecem a passagem, abrindo um leque de possíveis interpretações do adjetivo e qualificando o actante em questão.

Ainda no mesmo trecho, os enunciadores adaptam nomes de duas músicas da banda Queen com o nome "Lula" para apontá-las como "grandes sucessos". Tal adaptação pode ser compreendida também como uma ambiguidade, posto que, como já citado, os livros de maior destaque de Merval Pereira como escritor também dizem respeito ao expresidente Lula. Assim, as inteligências enunciativas encontram outra forma de satirizar Merval Pereira a partir do campo semântico da música, explorando ainda as aliterações e outros arranjos fonéticos. "Love Of My Life" vira "Lula of My Life" e "Radio GaGa" vira "Radio Lu La".

A última fala de "Mercuryval" no parágrafo evoca um horizonte referencial específico e polêmico que envolve o juiz Sérgio Moro, na desnotícia "Axl Moro": "E vai ter também aquele single da conversa entre o Lula e a Dilma lançado pelo Axl Moro!". No caso, o single diz respeito ao áudio de uma conversa entre Lula e Dilma divulgado em 2016 em que ambos tratam do "Bessias", uma pessoa que, supostamente, levaria a Lula um

17 Disponível em: https://michaelis.uol.com.br/moderno-portugues/busca/portugues-brasileiro/ mercurial/. Acesso em: 18 set. 2019.

18 Disponível em: https://en.oxforddictionaries.com/definition/mercurial. Acesso em: 18 set. 2019.

19 Disponível em: https://veja.abril.com.br/blog/sobre-palavras/mercurial-com-o-sentido-de8216-temperamental-8217-esta-certo/. Acesso em: 18 set. 2019. 
documento capaz de safá-lo da prisão à época ${ }^{20}$. Assim, percebe-se que os enunciadores mesclam elementos próprios do campo semântico da música, como "single" e o nome de um cantor famoso "Axl Rose", com antropônimos referentes à esfera jurídica brasileira, introduzindo a partir das figuras horizontes referenciais que os enunciatários devem reconhecer. Percebe-se, ainda, que os enunciadores escolhem as figuras com cautela, pois, por se tratar de um festival de música, o "single" só pode ser representado por uma faixa de áudio, exatamente no que consiste o "furo" realizado por Sérgio Moro na divulgação das informações de beneficiamento do presidente Lula por parte do governo.

No segundo parágrafo, mais figuras e horizontes referenciais são evocados para compor a desnotícia: "Mercuryval contou que o show deve começar pontualmente às duas da tarde, com a abertura dos New Kims on the Block, a boy band estriônica do MBL". Aqui, percebe-se a presença da figura "MBL", o Movimento Brasil Livre, sendo representada como uma "boy band" cujo nome é uma adaptação da boy band americana "New Kids on the Block"; na desnotícia, "Kids" vira "Kims" por conta do representante de maior destaque do citado MBL, Kim Kataguiri. Os enunciadores utilizam o adjetivo "estriônico"21, relativo à pessoa que se comporta de maneira exagerada ou que costuma fazer palhaçadas, para (des)qualificar o grupo. Essa escolha revela um ponto de vista do enunciador sobre a "boy band", o MBL, conhecido por ser um ferrenho grupo defensor do impeachment da expresidenta Dilma Rousseff ${ }^{22}$ e também da prisão do ex-presidente Lula ${ }^{23}$, responsável por convocar massivas manifestações de rua em defesa dessas causas através da internet, onde também mantém constante atividade militante.

Ainda no mesmo parágrafo, os enunciadores evocam as figuras de Deltan Dallagnol, Elton John, Rosa Weber e Rita Lee: "Logo depois ele sobe ao palco para fazer um dueto com o rockstar anglo-curitibano Deltan John. Em seguida, Mercuryval cede os vocais para a transmissão, ao vivo, do voto da ministra Rosa Weber, a Rita Lee do Supremo". Percebe-se que a adaptação de nomes e a correlação de figuras do âmbito político-jurídico e artístico são pensadas para trazer à tona na desnotícia essas duas esferas que, desde o início do texto, são realizadas de modo muito claro. É possível afirmar que o desfecho do "festival" está na última "atração" anunciada, o voto de Rosa Weber, que é equiparada à cantora

20 Disponível em: https://epoca.globo.com/tempo/noticia/2016/03/dilma-cai-em-grampo-da-pfem-conversa-com-lula.html. Acesso em 18 set. 2019.

21 Chama atenção o modo como o adjetivo está escrito na desnotícia, pois, segundo o dicionário, sua correta grafia é "histriônico" por ser relativo a "histrião", palavra derivada do latim. Fonte: https://michaelis.uol.com.br/moderno-portugues/busca/portugues-brasileiro/histri\%C3\%A3o/. Acesso em: 18 set. 2019.

22 Disponível em: https://www.valor.com.br/politica/4070648/mbl-protocola-pedido-deimpeachment-de-dilma. Acesso em: 18 set. 2019.

23 Disponível em: https://politica.estadao.com.br/noticias/geral,mbl-e-vem-pra-rua-convocamatos-pela-prisao-de-lula,70002240032. Acesso em: 18 set. 2019. 
Rita Lee. Não é citado, porém, qual o desfecho do festival, ficando pressuposto que se trata da condenação do ex-presidente Lula à prisão. Tal pressuposto, no entanto, também trata de um horizonte referencial o qual o enunciatário precisa reconhecer.

No último parágrafo da desnotícia, os enunciadores afırmam: "Os ingressos para o festival estão à venda em todos os grupos de família do WhatsApp". Aqui, a escolha pela figura dos "grupos de família do WhatsApp" revela que os enunciadores procuram atualizar o sentido de que se tratam de "locais" onde há intensa veiculação de propaganda contrária ao ex-presidente Lula, por isso podem oferecer ingressos para o espetáculo em que ele é condenado à prisão. Ao encontro dessa hipótese, é importante frisar que no mesmo mês em que a desnotícia em questão foi publicada, um estudo da USP revelou que os grupos de família são os principais vetores de notícias falsas no aplicativo WhatsApp. É possível que os enunciadores tivessem isso em mente ao utilizarem essa figura, porém nenhum elemento no texto aponta para a atualização de grandezas discursivas relativas às "fake news"24.

E, ao final da desnotícia, mais informações sobre a realização do evento: "Ainda há lugares disponíveis no Camaroti, o camarote do Camarotti". Percebe-se aqui a utilização de uma espécie de anáfora que adapta o sobrenome do jornalista e escritor Gerson Camarotti com o substantivo "camarote", um espaço separado da área comum em teatros e salas de espetáculo, para criar o efeito humorístico. Gerson Camarotti é comentarista político da GloboNews e autor de dois livros: Memorial do Escândalo (2005), sobre a crise política do governo petista de Lula, e Segredos do Conclave (2013), sobre a eleição do atual Papa Francisco. Trata-se de outro actante que, assim como Merval Pereira, exige um certo nível de conhecimento por parte do enunciatário acerca do cenário político brasileiro.

Assim, observa-se que, além do abundante investimento semântico que os actantes recebem, as escolhas dos actantes por si só demarcam a posição assumida pelos enunciadores frente ao assunto. Percebe-se que todos os envolvidos no grande "espetáculo" são personagens resgatadas do cenário político atual, a partir de um movimento interdiscursivo. Como foi demonstrado, todos os atores presentes no texto têm forte ligação com a militância antipetista, sendo descritos com intensa sensação de júbilo, pois se encontram numa situação de clímax, prestes a testemunhar o desfecho de um percurso narrativo conhecido pelo enunciatário. A sátira busca destacar que, dentro de um espectro político específico, a condenação de Lula é um "evento" muitíssimo desejado. Há uma sanha por "justiça" pelos crimes cometidos pelo ex-presidente por parte dos atores mencionados, sentimento este que alicerça inclusive a trajetória de muitos deles. A miríade de imagens e sentidos construídos pelas inteligências enunciativas satiriza de modo muito intenso essas características, conferindo investimento semântico mínimo apenas a Lula e Dilma, os actantes menos interessados no show prestes a se desenrolar.

24 Fonte: https://www.bbc.com/portuguese/brasil-43797257. Acesso em: 18 set. 2019. 


\section{À guisa da conclusão...}

A prática desnoticiosa foi abordada no presente trabalho a partir de seu princípio de funcionamento mais elementar: a presença dos processos de incorporação nas entrelinhas de seus enunciados. Como se viu, a abordagem tradicional da interdiscursividade e da intertextualidade ganhou complexidade quando o fazer persuasivo e o fazer interpretativo obtiveram estatuto de práticas no percurso gerativo da expressão criado por Jacques Fontanille (2008). Assim, compreende-se que a prática de interpretação dos enunciados consiste numa transformação intersemiótica cujos denominadores são o enunciado interpretativo e os horizontes referenciais, que funcionam como base à interpretação do enunciado.

Ao nível dos objetos-suportes, tal transformação intersemiótica ficou a cargo da organização formal dos elementos das homepages que, como se viu, procura emular ao máximo o que pratica o gênero noticioso comum: fontes, planos de fundo, seções, etiquetas, slogans e outros elementos formais trazem jornais prestigiosos e portais de notícias como horizontes referenciais. Já ao nível dos textos-enunciados, os horizontes referenciais evocados muitas vezes se interseccionam, porém são trabalhados de modo completamente distinto em cada um dos veículos.

No site Sensacionalista, como se viu, grande parte das "outras cenas" necessárias à interpretação do texto são constituídas por acontecimentos amplamente disseminados pela mídia. O texto conta majoritariamente com certo tom denunciatório, pois ao longo dos percursos narrativos procura atualizar grandezas discursivas como as da "perseguição" e do "conluio", quando falam da conduta da "PF" frente aos políticos do "PT".

O blog The Piauí Herald, por sua vez, explora antropônimos também massivamente veiculados pela mídia; no entanto, inova no revestimento temático e figurativo que dá a tais antropônimos, sobrepondo-os com outros pertencentes ao campo semântico musical, completamente distinto do jurídico. O texto do blog, portanto, pretende-se satírico ao conjugar figuras de jornalistas e juristas com vocalistas extravagantes, construindo ilusões referenciais que se pretendem absurdas, evocando no enunciatário um forte sentido de irrealidade.

Já o texto do site Sensacionalista traz uma lacuna de observação que nos leva diretamente ao enunciador da desnotícia: o "desabafo" que pede que o Partido dos Trabalhadores tome "vergonha na cara" aponta para uma tomada de posição que revela um certo apoio crítico ao actante "PT", pois ao mesmo tempo que denuncia o "conluio" que existe contra ele - atualizando e realizando formas discursivas que apontam para uma perseguição ao PT por parte das autoridades -, denunciam também a má conduta de alguns de seus membros. Na desnotícia do blog The Piauí Herald, não há qualquer manifestação do tipo por parte dos enunciadores, que preferem explorar um campo semântico destoante para satirizar os actantes envolvidos. 
Assim, conclui-se que ambos veículos são oriundos do mesmo gênero e lançam mão de elementos muito semelhantes; no entanto, enquanto os textos compostos pelo site evocam interdiscursos menos complexos e têm um esparso investimento semântico no revestimento dos actantes, o blog explora antropônimos específicos de um dado nicho da política brasileira e os sobrepõe ainda a outros, de campos semânticos distintos, exigindo de seu enunciatário mais do que simplesmente conhecimento acerca do contexto sociopolítico. Dessa forma, percebe-se um trabalho mais cerimonioso e pormenorizado por parte do blog. O site, por sua vez, adota um estilo menos nonsense, porém mais denunciatório e revelador daqueles que estão por trás das composições, como se viu. Percebe-se, assim, que as formas de trabalhar o discurso humorístico podem estar carregadas - ou não - de valores intrínsecos que revelam seus reais intuitos.

\section{REFERÊNCIAS}

BALDAN, M. de L. O. G. Veridicção: um problema de verdade. Alfa: Revista de Linguística, São Paulo, v. 32, p. 47-52, 1988. Disponível em: http://seer.fclar.unesp.br/alfa/article/ view/3797. Acesso em: 12 jan. 2016.

BRAIT, B. Ironia em perspectiva polifônica. Campinas: Editora da UNICAMP, 2008.

CAMPOS, K. R. Prática desnoticiosa e veridicção: um estudo sobre o site Sensacionalista e blog The Piaui Herald. 2019. Dissertação (Mestrado) - Faculdade de Ciências e Letras, Universidade Estadual Paulista "Júlio de Mesquita Filho", Araraquara, 2019.

CARVALHO, F. A semiótica social das cores e das formas tipográficas: conceitos, categorias e aplicações. Discursos contemporâneos em estudo, Brasília, v. 2, p. 47-56, 2013. Disponível em: https://www.cepadic.com/pdf/dcee2.pdf\#page=47. Acesso em: 22 dez. 2018.

FÁVERO, L. L. Paródia e Dialogismo. In: BARROS, D. L. P. de; FIORIN, J. L. (org.). Dialogismo, polifonia e intertextualidade: em torno de Bakhtin. São Paulo: Editora da Universidade de São Paulo, 1994.

FIORIN, J. L. Da necessidade da distinção entre texto e discurso. In: BRAIT, B.; SOUZA-ESILVA, M. C. (org.). Texto ou discurso? São Paulo: Contexto, 2012. p. 145-162.

FIORIN, J. L. Interdiscursividade e intertextualidade. In: BRAIT, B. (org.). Bakhtin: outros conceitos-chave. São Paulo: Contexto, 2006. p. 161-193. 
FIORIN, J. L. Polifonia textual e discursiva. In: BARROS, D. L. P. de; FIORIN, J. L. (org.). Dialogismo, polifonia e intertextualidade: em torno de Bakhtin. São Paulo: Editora da Universidade de São Paulo, 1994.

FONTANILLE, J. Pratiques sémiotiques. Paris: PUF, 2008.

FONTANILLE, J. Sémiotique et littérature. Essais de méthode. Paris: PUF, 1999.

GREIMAS, A. J.; COURTÉS, J. Dicionário de Semiótica. São Paulo: Editora Cultrix, 1979.

HERNANDES, N. A mídia e seus truques: o que jornal, revista, TV, rádio e internet fazem para captar e manter a atenção do público. São Paulo: Contexto, 2006.

SCHWARTZMANN, M. N. Cartas marcadas: Prática epistolar e formas de vida na correspondência de Mário de Sá-Carneiro. 2009. Tese. (Doutorado) - Faculdade de Ciências e Letras, Universidade Estadual Paulista "Júlio de Mesquita Filho", Araraquara, 2009. 